\title{
A new doctor in the house: hospital medicine in the United States
}

\author{
P. Basaviah, L. Goldman
}

\begin{abstract}
Within the past five years, the hospitalist model has emerged as a major new approach to inpatient medicine in the United States. Health care market forces, particularly the need for quality and efficiency in inpatient care, have served as the impetus for the model's accelerated growth. A burgeoning literature reinforces the notion that hospitalists improve efficiency of care and likely enhance education and quality of care. Hospitalists continue to make favorable impressions on the medical field as leaders in the practice, teaching, and research of hospital medicine as well as in the implementation of quality improvement initiatives. Despite concerns about the potential fragmentation of care, the risk of burnout among hospitalists, and low financial reimbursements, the hospitalist model has continued to grow and flourish. Patients and primary care physicians are increasingly accepting of the field, especially as hospitalists develop novel ways to improve communication at the interface of hospital and ambulatory practice.
\end{abstract}

\section{Key Words}

Hospitalists, Hospital Medicine, Quality, Cost, Medical Education, Patient Satisfaction.

\section{Introduction}

European physicians and experts in health care may be surprised by the increased attention on "hospitalists" in the United States. Exclusively hospital-based practices have been common for decades in Europe, especially the United Kingdom (U.K.) and Germany, and in Canada [1]. In the U.S., a hospitalist is defined as a physician who accepts principal responsibility for patients from a primary care physician (PCP) upon hospital admission, provides and/or supervises the inpatient care, and ultimately returns the patient to the care of the PCP upon discharge [2]. Although occasional physicians have served in such roles for decades, the hospitalist movement has grown dramatically in the last five to ten years, from several hundred practitioners to more than 4,000 today [3]. A new professional society, the National Association of Inpatient Physicians (NAIP), began in 1997 and has grown to nearly 2,000 members [4]. Experts project that the number of hospitalists in the U.S. will increase dramatically over the next few years, from the current 4,500 to 19,000 , a workforce comparable to the number of cardiologists in the U.S [1] and a per capita supply that would be lower than currently found in Germany but higher than the U.K [5].

In the U.S., the evolution of hospital care in specific locations has often progressed through four distinct stages, although many locales have jumped directly from stage I to stage IV. In stage I, PCPs manage their own hospital care; in stage II, PCPs develop a hospital rotational structure such that one member of the group periodically manages the inpatients of colleagues; in stage III, dedicated hospitalists receive patients voluntarily from; and, in stage IV, the transfers to the hospitalists are mandatory. Advantages and disadvantages exist at each stage [6].

\section{Background}

A complex combination of forces has accelerated the growth of the hospitalist model of inpatient care in the U.S. The rapid increase of capitated payment systems has imposed financial pressures on physicians, hospitals, and managed care groups. The imperative to practice cost-effective medicine while providing quality care underlies these pressures. Further, the need for inpatient expertise in caring for higher acuity patients is evident, especially as hospital stays shorten [7]. The search for value in a competitive marketplace has also placed premiums on efficiency and increased access to physicians in both inpatient and ambulatory settings $[8,9]$.

Additional barriers to practicing inpatient care, particularly for PCPs, exist. New time constraints restrict PCPs in the office, threatening productivity and patient/provider satisfaction. Limited in their exposure to and experience with hospitalized patients, PCPs may feel ill-equipped to handle increasingly complex conditions and 
Table 1

The Hospitalist Model in the United States.

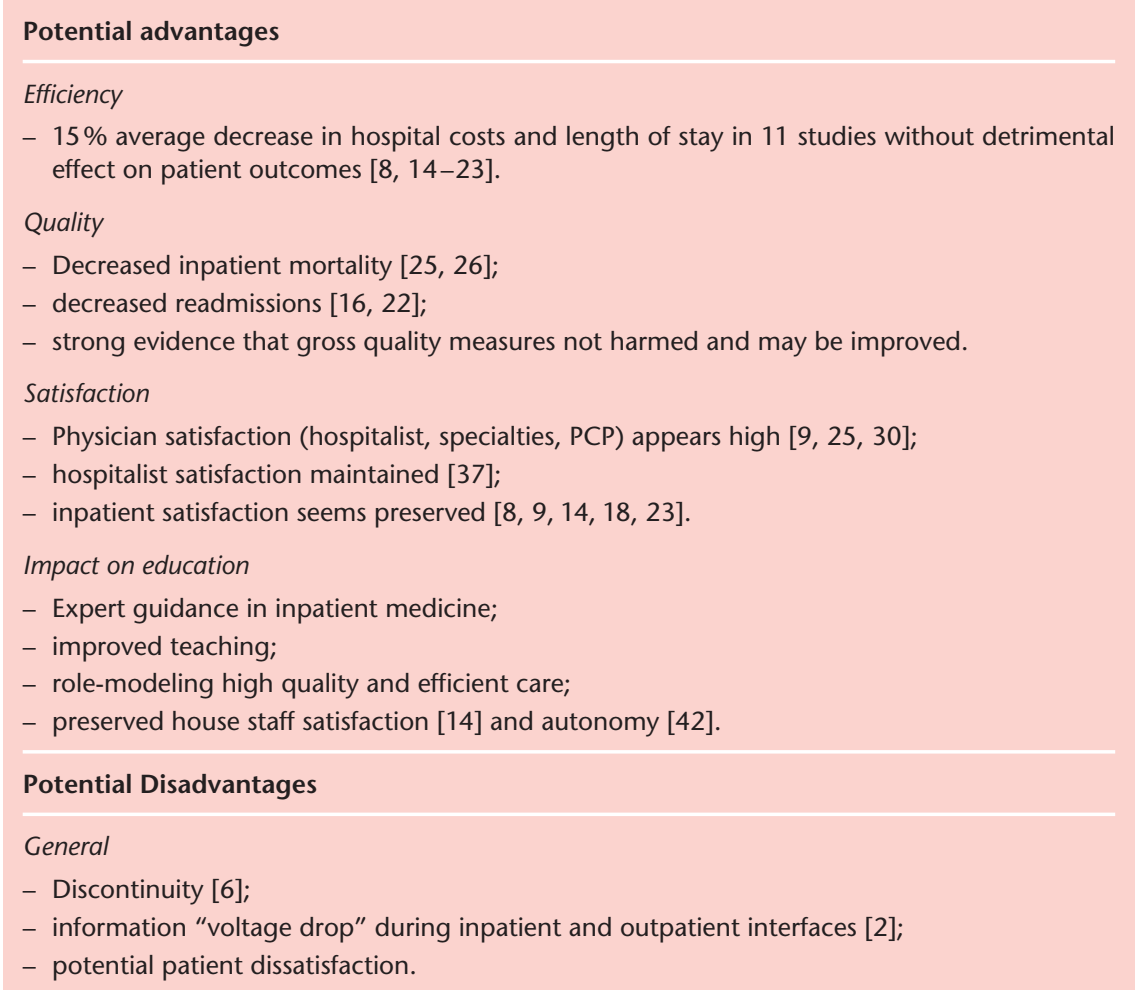

uncommon presentations. In one study of inpatient conditions treated by PCPs, $29 \%$ of conditions were treated three or more times per year, $25 \%$ were treated twice per year, and $46 \%$ were treated no more than once per year [10]. Decreasing volumes of inpatients for most PCPs put their inpatient skills under scrutiny, especially when data exist supporting higher quality of care with higher volumes and numbers of procedures in other medical fields [11-13]. The frenetic pace of outpatient practices and the growing distance between office and hospital further obstruct efforts of PCPs to meet their historic inpatient responsibilities [7]

The early phase of growth in hospital medicine was based on foundations of limited data and anecdotal findings. Recent published data have highlighted achievements in the field and informed future agendas in program development and research. Key issues in 2002 include: the growing body of research on value in hospitalist programs, the emphasis on continuity of care during hospitalization and during inpatient-outpatient transitions, the impact of hospital medicine on academia, expanding roles for hospitalists, the debate over creating a new specialty, and financial implications [7].

\section{What are hospitalists' impact on efficiency and quality (tab. 1)?}

The dominant rationale driving the hospitalist model is that physicians skilled in the care of inpatients can improve both the quality and the efficiency of hospital care. A growing body of literature suggests that hospitalist systems result in increased efficiency of care for inpatients with preserved or improved patient outcomes. Strong evidence exists for decreased hospital costs and length of stay, with an average reduction of $15 \%$ noted in 11 studies [8, 14-23]. This consistent demonstration of clinical efficiency without a detrimental effect on patient outcomes extends to different practice settings, such as a large health-maintenance organization [24], a community teaching hospital [22], and an academic medical center [14]. No excess mortality has occurred $[9,14,17,24]$, and two groups have demonstrated significant reductions in inpatient and short-term mortality $[22,23]$. Though there is also some evidence of reduced readmission rates $[16,27]$ and decreased emergency room revisits after discharge from a hospitalist service [28], these findings are not consistent across all studies.

The current literature on quality of care, though intriguing, is at this time insufficient to confirm the notion that hospitalists improve quality. Additional research is warranted and should use more precise measures of both processes and outcomes, including measures of appropriateness and post-discharge functional status.

Several factors may contribute to hospitalists' efficiency. Efficiency can occur during discharge planning because of more continuous contact with case managers or social workers, or because hospitalists can facilitate discharges in the afternoon rather than after the next morning's visit. The hospitalist model may also permit greater efficiency for busy outpatient physicians who are now freed from inpatient responsibilities. Importantly, the hospitalist model has the theoretical potential for improved patient outcomes. Because they are in the hospital throughout the day, hospitalists may be able to react to changes in a patient's clinical status more quickly [22].

\section{Is patient satisfaction maintained?}

Initial concerns focused on potential patient dissatisfaction with having physicians unfamiliar to them supplant their PCPs in supervising their inpatient care. Proponents of hospitalist systems 
postulated that the hospitalists' availability and inpatient expertise could mitigate these concerns $[6,27]$. In fact, inpatients cared for by hospitalists demonstrate high levels of satisfaction, no lower than that of inpatients managed by their own PCPs $[8,9,18]$ or by traditional academic attendings-of-the-month [14, 23].

\section{Is PCP satisfaction maintained?}

Fragmentation between providers and services is commonly identified as a significant obstacle to maintaining high-quality and efficient care. Nevertheless, both generalists and specialists surveyed at Park Nicollet expressed positive impressions several years after the implementation of a hospitalist system [9]. A national phone survey of 400 generalists revealed that most (51\%) felt hospitalists might provide better care, and $47 \%$ felt patients might receive more cost-effective care [22]. In a survey of 524 PCPs in Northern California, most PCPs thought hospitalists increased (41\%) or did not change (44\%) quality, $53 \%$ believed that hospitalists decreased their workload, and $55 \%$ felt that hospitalists improved efficiency [28].

Critics of hospitalist systems point to a disruption in the continuity of care and a potential "voltage drop" of information during inpatientoutpatient transitions [2]. Phoning primary care physicians on admission and discharge, faxing progress notes or discharge summaries, and encouraging continuity visits or calls from PCPs during hospitalization represent effective methods for addressing these concerns [7]. PCPs overwhelmingly reported that they "very much prefer" to communicate with hospitalists by telephone at admission and discharge. In terms of information to be transferred, these PCPs consistently rated only discharge medications and discharge diagnosis to be "very important" [29].

\section{Are there potential disadvantages?}

The major potential disadvantage of hospitalist systems concerns the purposeful discontinuity inherent to the transitions between admission and discharge, or the "hand-off" between hospitalists and primary care physicians [6]. As noted above, hospitalists have developed a series of approaches to meet these communication challenges.

A key issue revolves around whether the use of hospitalists should be mandatory, a policy that was developed by some managed care organizations but which sparked vehement opposition from many physicians and from several professional societies [30, 31]. As a result, creation of mandatory programs by managed care orga- nizations has become the exception [3], and physicians and professional groups have increasingly accepted voluntary hospitalist programs [28, 32, 33].

\section{Are hospitalists satisfied with their careers?}

In a recent survey, practicing hospitalists reported choosing this field for its "intellectual stimulation and enjoyment," "chance to be involved in an emerging specialty," and "chance to have a job with predictable hours and lifestyle" [34]. In 1997, a NAIP survey found that nearly all hospitalists were satisfied with their current positions, and more than three quarters intended to be hospitalists three years into the future [35]. Although professional "burnout" or exhaustion remains a crucial concern, a 1999 NAIP survey found that $64 \%$ of hospitalists expected to be hospitalists in 7 years [34]. Further questioning revealed that $62 \%$ were at no current risk of burnout, $25 \%$ were at risk, and $13 \%$ were burned out. These rates are considerably lower than the 40-60\% burnout rate reported by intensivists [36] and emergency medicine physicians in the U.S. [37].

\section{What are current educational issues in hospital medicine?}

\section{Implications for Medical Training and Staffing}

Academic hospitalists have emerged as core educators of inpatient medicine [7]. Educational benefits are reflected in hospitalists' expertise in inpatient medicine, their availability to teach throughout the day, and their role-modeling characteristics regarding high quality and efficient care. Hospitalists' presence on the inpatient wards affords unique opportunities for bedside teaching as well as direct observation of work rounds with trainees. For example, UCSF's 15 faculty hospitalists staff nearly two-thirds of all months of inpatient attending and medical consultation. This redesign of the inpatient medical service was intended to improve quality of care and decrease costs, but it also succeeded in preserving housestaff satisfaction [14]. In fact, the hospitalists have earned teaching evaluations that are significantly higher than those of the carefully selected non-hospitalists who attend for one month each per year.

In training programs that have adopted the hospitalist model, the ward-attending workforce has changed from a diverse combination of physicians (including non-hospitalist generalists, clinical subspecialists, and biomedical researchers) to a majority of generalist-hospitalists. This shift in workforce potentially limits a 
trainee's exposure to the broad range of expertise that a full faculty embodies [40]. In response, residency programs have had to initiate new ways to engage these other physician-teachers via morning report, noon conferences, and special rounds.

In addition, though real-time instruction and expert guidance on the wards is invaluable, a hospitalist's easy accessibility potentially threatens the need for residents to develop autonomy. Preliminary evidence dispels these concerns, finding maintained or increased house staff satisfaction [14, 39] with a hospitalist system because of improved teaching, expert guidance, and emphasis on helping trainees achieve appropriate but not premature autonomy [42].

\section{Preparation for Hospitalist Careers}

Initially, hospitalists hailed from a variety of backgrounds, and no unique training programs existed for hospitalists. In a 1997 NAIP survey, training profiles spanned general medicine (50\%) and medical subspecialties $(40 \%$, of which half were pulmonologists and/or critical care specialists), with family physicians and pediatricians comprising the remainder [35]. Within two years, the generalist portion had expanded to $75 \%$ of the workforce, with subspecialists composing only $15 \%$ [34].

Several medical centers have now established residency tracks and/or fellowships to provide further training in inpatient medicine, research, and teaching skills. The first fellowship and the first residency track began at UCSF in 1998, and additional fellowships have been developed at University of Illinois / Carle Foundation Hospital, Oregon Health Sciences University, Emory / Grady Memorial Hospital, Cleveland Clinic, University of Minnesota / HealthPartners, and Mayo Clinic [41]. Residency tracks and electives are offered at Beth Israel Deaconess Medical Center in Massachusetts, Wake Forest University in North Carolina, and Emory University in Georgia.

The curricula for hospitalist training programs initially have been based, in part, on surveys in which practicing hospitalists rated the adequacy of their training for their current clinical practices [42]. Of note, hospitalists cited clinical skills, such as inserting central lines and interpreting electrocardiograms as highly important and as been having well taught during residency. However, they noted major "educational deficits" in communication skills, endof-life care, quality improvement and patient safety, medical economics, care of surgical patients, and post-acute care. These findings have catalyzed efforts to develop core competencies for future training programs for hospitalists.

\section{What is the impact on the academic sector?}

The rise of the hospitalist paradigm in academia has not only had positive influences on patient care, quality, and education, but also has inspired novel research efforts [43]. The research agenda began with evaluating the effects of the hospitalist model itself. Now, academic hospitalists are increasingly applying the principles of health services and outcomes research, ethics, and clinical epidemiology [7] to study essential inpatient issues, including facilitating end-oflife care [44], preventing nosocomial infections [45], and measuring quality markers.

\section{How have hospitalists' job descriptions expanded?}

Initially, hospitalists participated principally in supervising the care of hospitalized medical patients and providing medical consultations for inpatients on non-medical services. Hospitalists now play expanding roles in both clinical and non-clinical settings. Consultation, pre-operative assessments, co-management of surgical patients, coverage of intensive care units (ICU), and/or supervising care in skilled nursing facilities represent new additions to the hospitalist's clinical job description. Hospitalists' availability and presence in the hospital have also led to new roles coordinating inter-hospital transfers and triaging patients in the emergency department [35]. In addition to these clinical roles, hospitalists often lead local and national efforts to derive and implement practice guidelines, develop quality improvement initiatives, manage informational technology projects, and direct educational programs for medical students and residents.

Whether the role of hospitalists will extend to the ICU remains to be seen. The majority (80\%) of hospitalists care for their own patients in ICUs [35], often requesting consultation from intensivists. Although studies suggest improved outcomes and efficiency when intensivists collaborate in the care of critically ill patients [46-48], the comparison groups were not hospitalists (i.e., they were either non-hospitalist ward attendings or community-based community physicians). Further research is warranted to compare the combination of hospitalist-based intensive care and intensivist consultation with care solely by an intensivist. 


\section{Hospital Medicine: A new specialty?}

Medical specialties in the U.S. have traditionally been defined as disease-based (e.g. oncology), organ-based (e.g. cardiology, nephrology), population-based (e.g. geriatrics, pediatrics), and technology- or procedure-based (e.g. radiology, electrophysiology). Recently, clinical practice sites have defined a new genre of specialties based on location (e.g. critical care, emergency medicine), an approach that could also include hospitalists [6]. But is hospital medicine truly a specialty? Can a generalist be a specialist? On most fronts, the field of hospital medicine meets the criteria for being called a specialty. A separate group consciousness pervades the growing body of physicians who eagerly self-identify as hospitalists. A professional society (NAIP) is flourishing. Distinct residency and fellowship programs, separate programs in continuing medical education, and distinct educational materials (e.g. textbooks) have spearheaded the expanding field of knowledge. Another criterion, the presence of definable and distinct competencies, is currently being addressed by national educational committees.

If hospital medicine is to be recognized as a medical specialty, however, credentialing organizations such as the American Board of Internal Medicine (ABIM) will have to create processes for examinations and, ultimately, the awarding of board certification or added qualifications [49]. Currently, many physicians fear that creation of a hospital medicine credential by an accrediting organization such as the ABIM would induce hospitals and managed care organizations to require that physicians obtain this new credential if they are to supervise inpatient care. In part because such action could exclude many PCPs from caring for their hospitalized patients, neither NAIP nor the ABIM are presently advocating separate credentials for hospital medicine [7].

\section{What are the financial implications of a hospitalist model?}

In most parts of the U.S., hospitalist programs are unlikely to be financially viable based on professional fee compensation alone. Hospitalists perform few procedures, receive relatively low compensation for non-procedural care, and often have an adverse payer mix [50]. In academic settings, the significant time spent on the formal and informal education of trainees requires substantial time but generates no clinical revenues. Most successful hospitalist programs depend on financial support from their hospitals or medical groups in recognition of their roles in improving quality, saving costs, and solidifying the educational mission.

\section{Conclusions}

The hospitalist movement has gained dramatic momentum in the U.S. in the past five years. Both academic and community hospitals are increasingly relying on hospitalists for the delivery of inpatient care. Evidence supports hospitalistassociated reductions in length of stay and cost without compromising, and likely enhancing, patient care, quality, and education. Hospitalists therefore are likely to become the primary providers of inpatient care in the U.S.

Although politics pervaded the initial discussions of hospital medicine, financial viability and professional sustainability now are at the forefront. Creative schedules and methods of communication between hospitalists and nonhospitalists can address potential drawbacks such as professional burnout, communication barriers, and discontinuity of care. The merits of a hospitalist program should be evaluated, preferably by randomized, controlled studies that measure quality, patient satisfaction, cost, efficiency, and impact on education and job satisfaction in various settings. 


\section{References}

1 Lurie JD, Miller DP, Lindenauer PK, Wachter RM, Sox HC. The potential size of the hospitalist workforce in the United States. Am J Med 1999; 106:441-5.

2 Wachter RM, Goldman L. The emerging role of «hospitalists» in the American health care system. N Engl J Med 1996;335:514-7.

3 Wachter RM. Debunking myths about the hospitalist movement. Am J Med 2000;108:672-3.

4 http://www.naiponline.org. National Association of Inpatient Physicians. Vol. 2001, 2001.

5 Organization for Economic Cooperation and Development. OECD Health Data 96. Paris, 1996.

6 Wachter RM. An introduction to the hospitalist model. Ann Intern Med 1999;130:338-42.

7 Wachter RM, Goldman L. The hospitalist movement five years later. JAMA 2002;287(4): 487-94.

8 Davis KM, Koch KE, Harvey JK, Wilson R, Englert J, Gerard PD. Effects of hospitalists on cost, outcomes, and patient satisfaction in a rural health system. Am J Med 2000;108:621-6.

9 Freese RB. The Park Nicollet experience in establishing a hospitalist system. Ann Intern Med 1999;130:350-4.

10 Falk C, Miller C. Hospitalist programs: Towards a new practice of inpatient care. Washington, DC: Advisory Board Company; 1998.

11 Dudley RA, Johansen KL, Brand R, Rennie DJ, Milstein A. Selective referral to high-volume hospitals: estimating potentially avoidable deaths. JAMA 2000;283:1159-66.

12 McGrath PD, Wennberg DE, Dickens JD Jr, Siewers AE, Lucas FL, Malenka DJ, et al. Relation between operator and hospital volume and outcomes following percutaneous coronary interventions in the era of the coronary stent. JAMA 2000;284:3139-44.

13 Magid DJ, Calonge BN, Rumsfeld JS, Canto JG, Frederick PD, Every NR, et al. Relation between hospital primary angioplasty volume and mortality for patients with acute MI treated with primary angioplasty vs thrombolytic therapy. JAMA 2000;284:3131-8.

14 Wachter RM, Katz P, Showstack J, Bindman AB, Goldman L. Reorganizing an academic medical service: impact on cost, quality, patient satisfaction, and education. JAMA 1998;279: 1560-5.

15 Stein MD, Hanson S, Tammaro D, Hanna L, Most AS. Economic effects of community versus hospital-based faculty pneumonia care. J Gen Intern Med 1998;13:774-7.

16 Diamond HS, Goldberg E, Janosky JE. The effect of full-time faculty hospitalists on the efficiency of care at a community teaching hospital. Ann Intern Med 1998;129:197-203.

17 Bellet PS, Whitaker RC. Evaluation of a pediatric hospitalist service: impact on length of stay and hospital charges. Pediatrics 2000;105:478-84.
18 Halpert AP, Pearson SD, LeWine HE, McKean SC. The impact of an inpatient physician program on quality, utilization, and satisfaction. Am J Manag Care 2000;6:549-55.

19 Kearns PJ, Wang CC, Morris WJ, Low DG, Deacon AS, Chan SY, Jensen WA. Hospital care by hospital-based and clinic-based faculty: a prospective, controlled trial. Arch Intern Med 2001;161:235-41.

20 Hackner D, Tu G, Braunstein GD, Ault M, Weingarten S, Mohsenifar Z. The value of a hospitalist service: efficient care for the aging population? Chest 2001;119:580-9.

21 Molinari C, Short R. The effects of an HMOhospitalist program on inpatient utilization. Am J Manag Care 2001;7(11):1051-7.

22 Auerbach AD, Wachter RM, Katz PP, Kerr K, Showstack J, Baron B, Goldman L. Implementation of a hospitalist service at a community teaching hospital: evolution of resource use and patient outcomes. Ann Intern Med (in press).

23 Meltzer D, Manning W, Morrison J, Shah M, Jin L, Guth T, Levinson W. Effects of physician experience on costs and outcomes on an academic general medicine service: results of a trial of hospitalists. Ann Intern Med (in press).

24 Craig DE, Hartka L, Likosky WH, Caplan WM, Litsky P, Smithey J. Implementation of a hospitalist system in a large health maintenance organization: the Kaiser Permanente experience. Ann Intern Med 1999;130:355-9.

25 Abenhaim HA, Kahn SR, Raffoul J, Becker MR. Program description: a hospitalist-run, medical short-stay unit in a teaching hospital. CMAJ 2000;163:1477-80.

26 Markoff BA, Kumra V, Menezes SN, MacMillan JF. The effect of academic hospitalist on readmission rates and cost per patient [abstract]. National Association of Inpatient Physicians, 3rd annual meeting, Philadelphia, PA, April 11-12, 2000.

27 Wachter RM. The hospitalist movement: ten issues to consider. Hosp Pract (Off Ed) 1999; 34(2):95-8, 104-6, 111.

28 Fernandez A, Grumbach K, Goitein L, Vranizan K, Osmond DH, Bindman AB. Friend or foe? How primary care physicians perceive hospitalists. Arch Intern Med 2000;160:2902-8.

29 Pantilat SZ, Lindenauer PK, Katz P, Wachter RM. Reach out and touch someone: primary care physician experience and communication with hospitalists. J Gen Intern Med 1999;14:62.

30 Maguire P. Use of mandatory hospitalists blasted. College, there protest plans that force doctors to give up inpatient care. ACP Observer 1999;19:20.

31 Foubister V. Doctors decry mandatory hospitalists. AMA News 1999;42:16-8.

32 Sox HC. The hospitalist model: perspectives of the patient, the Internist, and internal medicine. Ann Intern Med 1999;130:368-72.

33 Auerbach AD, Nelson EA, Lindenauer PK, Pantilat SZ, Katz PP, Wachter RM. Physician attitudes toward and prevalence of the hospitalist model of care: results of a national survey. Am J Med 2000;109:648-53. 
34 Hoff TH, Whitcomb WF, Williams K, Nelson JR, Cheesman RA. Characteristics and work experiences of hospitalists in the United States. Arch Intern Med 2001;161:851-8.

35 Lindenauer PK, Pantilat SZ, Katz PP, Wachter RM. Hospitalists and the practice of inpatient medicine: results of a survey of the National Association of Inpatient Physicians. Ann Intern Med 1999;130:343-9.

36 Guntupalli KK, Fromm RE Jr. Burnout in the internist-intensivist. Intensive Care Med 1996; 22:625-30.

37 Goldberg R, Boss RW, Chan L, Goldberg J, Mallon WK, Moradzadeh D, et al. Burnout and its correlates in emergency physicians: four years' experience with a wellness booth. Acad Emerg Med 1996;3:1156-64.

38 Hauer KE, Wachter RM. Implications of the hospitalist model for medical students' education. Acad Med 2001;76:324-30.

39 Brown MD, Halpert A, McKean S, Sussman A, Dzau VJ. Assessing the value of hospitalists to academic health centers: Brigham and Women's Hospital and Harvard Medical School. Am J Med 1999;106:134-7.

40 Goldman L. Specialized tracks, or one size does not fit all! ABIM Report 2000:57-61.

41 Kriplani N. Hospitalist fellowships on the rise. Hospitalist 2001: In press.
42 Plauth WH 3rd, Pantilat SZ, Wachter RM, Fenton CL. Hospitalists' perceptions of their residency training needs: results of a national survey. Am J Med 2001;111(3):247-54.

43 Goldman L. The impact of hospitalists on medical education and the academic health system. Ann Intern Med 1999;130:364-7.

44 Pantilat SZ, Alpers A, Wachter RM. A new doctor in the house: ethical issues in hospitalist systems. JAMA 1999;282:171-4.

45 Saint S, Matthay MA. Risk reduction in the intensive care unit. Am J Med 1998;105:515-23.

46 Pollack MM, Katz RW, Ruttimann UE, Getson PR. Improving the outcome and efficiency of intensive care: the impact of an intensivist. Crit Care Med 1988;16:11-7.

47 Manthous CA, Amoateng-Adjepong Y, al-Kharrat T, Jacob B, Alnuaimat HM, Chatila W, Hall JB. Effects of a medical intensivist on patient care in a community teaching hospital. Mayo Clin Proc 1997;72:391-9.

48 Young MP, Birkmeyer JD. Potential reduction in mortality rates using an intensivist model to manage intensive care units. Eff Clin Pract 2000;3:284-9.

49 Kelly M. The hospitalist: a new medical specialty? Ann Intern Med 1999;130:373-5.

50 Wachter RM, Whitcomb WF, Nelson JR. Financial implications of implementing a hospitalist program. Healthc Financ Manage 1999;53:48-51. 